REVUE DE L'INSTITUT

FRANÇAIS D'HISTOIRE

EN ALLEMAGNE

\section{Revue de l'IFHA}

Revue de l'Institut français d'histoire en Allemagne

$4 \mid 2012$

IFHA 4

\title{
Le 49e congrès des historiens allemands (Historikertag)
}

Mayence du 25 au 28 septembre 2012

Pierre Monnet

\section{OpenEdition}

\section{Journals}

Édition électronique

URL : http://journals.openedition.org/ifha/400

DOI : $10.4000 /$ ifha. 400

ISSN : 2198-8943

\section{Éditeur}

IFRA - Institut franco-allemand (sciences historiques et sociales)

Édition imprimée

Date de publication : 30 septembre 2012

Pagination : 81-83

ISSN : 2190-0078

\section{Référence électronique}

Pierre Monnet, "Le 49e congrès des historiens allemands (Historikertag) », Revue de I'IFHA [En ligne], 4 I 2012, mis en ligne le 14 février 2013, consulté le 15 septembre 2020. URL : http://

journals.openedition.org/ifha/400

Ce document a été généré automatiquement le 15 septembre 2020

(C)IFHA 


\section{Le $49 \mathrm{e}$ congrès des historiens allemands (Historikertag)}

Mayence du 25 au 28 septembre 2012

\section{Pierre Monnet}

\section{NOTE DE L'ÉDITEUR}

\section{Présentation par Pierre Monnet}

1 Depuis des décennies, le congrès des historiens allemands (Historikertag) se tient tous les deux ans dans une université allemande (pour ne citer que les dernières éditions : 1994 à Leipzig, 1996 à Munich, 1998 à Francfort-sur-le-Main, 2000 à Aix-la-Chapelle, 2002 à Halle, 2004 à Kiel, 2006 à Constance, 2008 à Dresde et 2010 à Berlin). L'édition 2012 est accueillie par l'université de Mayence. Après la question de l'anthropologie et de la science (1994), de l'histoire comme argument (1996), des intentions et des réalités (1998), de l'histoire mondiale (2000), des traditions et des visions (2002), de la communication et de l'espace (2004), des images de/dans l'histoire (2006), des inégalités (2008) et des frontières (2010), le présent congrès de Mayence retient pour sujet d'étude les ressources et les conflits (consulter le site dédié au congrès : http:// www.historikertagde/Mainz2012/de/startseite.html).

2 Cette thématique, d'une brûlante actualité, est à comprendre en un sens pratique, matériel et technique (gestion des ressources par les sociétés humaines dans la longue durée et conflits générés par leur partage) et en un sens symbolique et intellectuel (ressources iconographiques, documentaires et imaginaires des hommes et des historiens qui les étudient, et conflits d'interprétation pour élucider cette histoire). Elle est traitée et déclinée à travers une cinquantaine de sections, un Forum réunissant une quarantaine de doctorants, un programme à destination des scolaires, des expositions, un salon de plus d'une centaine d'éditeurs scientifiques et quatre espaces de présentation. 
3 Traditionnellement, le congrès réunit entre 3000 et 3500 participants, ce qui en fait le congrès scientifique le plus important d'Europe en sciences sociales et humaines. À côté des historiens universitaires et des chercheurs de profession, des étudiants et des doctorants, la manifestation rassemble en effet les enseignants d'histoire des lycées, les documentalistes, bibliothécaires, éditeurs scientifiques et créateurs de sites et de bases de données, mais aussi les responsables de laboratoires et de centres de recherche des facultés et des institutions extra-universitaires de recherche. Il est organisé par le Deutscher Historikerverband, actuellement présidé par le professeur Werner Plumpe, professeur d'histoire économique et sociale contemporaine à l'université Goethe de Francfort-sur-le-Main.

Il est toujours ouvert par des personnalités de haut rang, la chancelière Angela Merkel en 2010, le président de la République Horst Köhler en 2008, le président du Bundestag Norbert Lammert en 2006. Cette année, il a été inauguré le mardi 25 septembre au soir en présence d'Andreas Vosskuhle, président de la cour constitutionnelle allemande (Bundesverfassungsgericht), de Kurt Beck, ministre-président du Land de RhénaniePalatinat et de l'ambassadeur de France en Allemagne, Maurice Gourdault-Montagne. En effet, la France est invitée d'honneur de cet événement, dans une ville au passé franco-allemand marqué, et également en considération de la coopération étroite tissée entre les communautés française et allemande d'historiens, à quelques mois de la célébration du 50e anniversaire de la signature du traité de l'Élysée en 1963, dont l'esprit a également insufflé un rapprochement scientifique crucial au regard de la place que l'histoire et son interprétation ont toujours occupée dans la définition et la perception de l'autre entre les deux pays (on peut ici songer à la fondation de l'Institut historique allemand de Paris en 1958, à celle de la Mission historique française en Allemagne de Göttingen en 1977 devenue en 2009 l'Institut français d'histoire en Allemagne de Francfort, à la création du Centre Marc Bloch à Berlin en 1992, à la constitution du CIERA à Paris en 1999).

5 La présence française des historiens (une douzaine au total) et de l'historiographie française a été conçue de plusieurs manières. Tout d'abord, le 27 septembre, JeanClaude Schmitt (EHESS) prononce la conférence festive du congrès sur le thème du temps et des rythmes comme ressources de l'historien. La veille, 26 septembre, une manifestation co-organisée par l'Institut français de Mayence et l'IFHA a convié Nicolas offenstadt (univ. Paris I-Panthéon-Sorbonne) à une conférence suivie d'un débat sur le thème des historiens et de la commémoration. D'autre part, l'IFHA (Pierre Monnet) et l'Institut historique allemand de Paris, IHAP (Gudrun Gersmann) animent une session de présentation conjointe de leurs deux institutions de recherche française sur l'Allemagne (IFHA) et allemande sur la France (IHAP). L'IHAP présente également au cours d'une section la collection «Deutsch-Französische Geschichte » en 11 volumes dont il encadre la publication depuis plusieurs années (voir la présentation de cette série dans le présent numéro de la Revue), tandis que le manuel d'histoire franco-allemand fait également l'objet d'une session dédiée (voir le rapport scientifique du colloque international de Bordeaux sur ce manuel dans la présente Revue à laquelle participe $\mathrm{P}$. Monnet pour l'IFHA). Une session organisée par le département d'histoire de l'université de Mayence porte sur «Frankreich-Deutschland: Von der Erbfeindschaft zur Erbfreundschaft ». Par ailleurs, deux espaces d'exposition accueillent des présentations institutionnelles françaises ou franco-allemandes. Le premier, intitulé «bistro scientifique", permet de présenter les travaux de la jeune génération scientifique. 
L'IFHA en fait partie par le biais de posters de ses doctorants et post-doctorant et d'un stand présentant ses activités et ses publications. Il y côtoie le CIERA, le Centre Marc Bloch de Berlin, l'IHAP et l'Université franco-allemande avec les cursus intégrés (dont celui conclu entre Dijon et Mayence, entre autres) et les collèges doctoraux francoallemands qu'elle soutient en histoire. Un second espace plus institutionnel sert à présenter les institutions actives dans la coopération culturelle franco-allemande avec l'institut français de Mayence, les maisons de Bourgogne à Mayence et de RhénaniePalatinat à Dijon ainsi que les sociétés franco-allemandes et les grands jumelages.

6 L'IFHA a suggéré que dans l'un de ces deux espaces publics soit organisée la présentation de toutes les entreprises achevées ou en cours des "Lieux de mémoire ", un concept inauguré et traduit en France par les volumes dirigés par Pierre Nora et qui a ensuite essaimé sous la forme des «Lieux de mémoire allemands » (Étienne François et Hagen Schulze), des «Lieux de mémoire européens » (Pim den Boer et al., 3 vol. en cours), des «Lieux de mémoire germano-polonais » (Hans Henning Hahn et Robert Traba, 3 vol. en cours) etc. 